LA-UR-03- 2893

Approved for public release; distribution is unlimited.

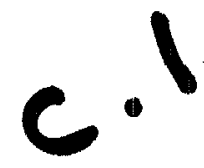

Title:

THE SNS LINAC HIGH POWER RF SYSTEM DESIGN, STATUS, AND RESULTS

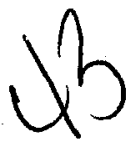

Submitted to:

Rees, Daniel

Bradley III, Joseph

Cummings, Karen

Hardek, Thomas

Roybal, William

Tallerico, Paul

IEEE PAC 2003

Portland, OR

May $12-16,2003$

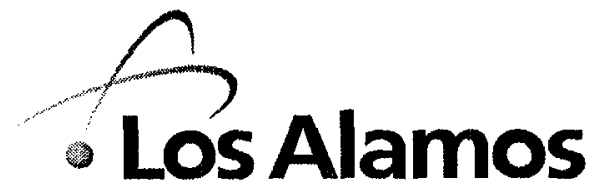

NATIONAL LABORATORY

Los Alamos National Laboratory, an affirmative action/equal opportunity employer, is operated by the University of California for the U.S. Department of Energy under'contract W-7405-ENG-36. By acceptance of this article, the publisher recognizes that the U.S. Government retains a nonexclusive, royalty-free license to publish or reproduce the published form of this contribution, or to allow others to do so, for U.S. Government purposes. Los Alamos National Laboratory requests that the publisher identify this article asmart performed under the auspices of the U.S. Department of Energy. Los Alamos National Laboratory strongly supports academic $\equiv$ lom and a researcher's right to publish; as an institution, however, the Laboratory does not endorse the viewpoint of a publication or guarc.... its technical correctness. 


\title{
THE SNS LINAC HIGH POWER RF SYSTEM DESIGN, STATUS, AND RESULTS*
}

\author{
D. Rees, J. Bradley III, K. Cummings, T. Hardek, W. Roybal, P. Tallerico LANL, Los Alamos, New \\ Mexico, 87544 USA
}

\begin{abstract}
The Spallation Neutron Source being built at the Oak Ridge National Lab in Tennessee requires a $1 \mathrm{GeV}$ proton linac. Los Alamos has responsibility for the RF systems for the entire linac. The linac requires 3 distinct types of RF systems: $2.5-\mathrm{MW}$ peak, $402.5 \mathrm{MHz}$, RF systems for the RFQ and DTL (7 systems total); 5-MW peak, 805 $\mathrm{MHz}$ systems for the CCL and the two energy corrector cavities (6 systems total); and $550-\mathrm{kW}$ peak, $805 \mathrm{MHz}$ systems for the superconducting sections (81 systems total). The design of the SNS Linac RF system was presented at the 2001 Particle Accelerator Conference in Chicago. Vendors have been selected for the klystrons (3 different vendors), circulators (1 vendor), transmitter (1 vendor), and high power RF loads (3 different vendors). This paper presents the results and status of vendor procurements, test results of the major components of the Linac RF system and our installation progress.
\end{abstract}

\section{SNS HIGH POWER RF EQUIPMENT}

A summary of the status of each of the high power RF components and a description of the problems encountered is provided below.

\section{Klystrons}

The SNS klystrons are supplied by three manufacturers. The specifications for each type of SNS klystron are given in Table 1. The 2.5-MW, $402.5 \mathrm{MHz}$ klystrons are supplied by E2V Technologies (formerly Marconi \& EEV). The 5.0-MW, $805 \mathrm{MHz}$ klystrons are supplied by Thales (formerly Thomson). The $550 \mathrm{~kW}, 805 \mathrm{MHz}$ klystrons are supplied by two manufacturers, CPI (formerly Varian) and Thales. A photograph of the 402.5 MHz klystron installed at Los Alamos is included in Fig. 1 and a photograph of the CPI $550 \mathrm{~kW}$ klystron and the Thales 5 MW klystron side by side is shown in Fig. 2 . The klystrons operate in a vertical orientation with localized shielding and are mounted into a socket attached to the lid of an oil tank. They are protected from high reflected power by a circulator. The $805 \mathrm{MHz}$ klystrons have a separate magnet while the $402.5 \mathrm{MHz}$ klystron has an integral magnet.

\subsection{MHz, 2.5 MW Klystrons}

As of the end of March 2003, eight $402.5 \mathrm{MHz}$ klystrons have been delivered by E2V Technologies. Of these 8 klystrons five have passed a site acceptance test, one is currently in test, one developed a vacuum leak during the site acceptance tests, and one developed a vacuum leak in shipping.
We accepted the first two klystrons at a reduced power (approximately 1.7 MW instead of the required $2.5 \mathrm{MW}$ ) to make schedule progress and because the first 2 sockets for the RFQ and DTL-1 required less than $1 \mathrm{MW}$ of RF

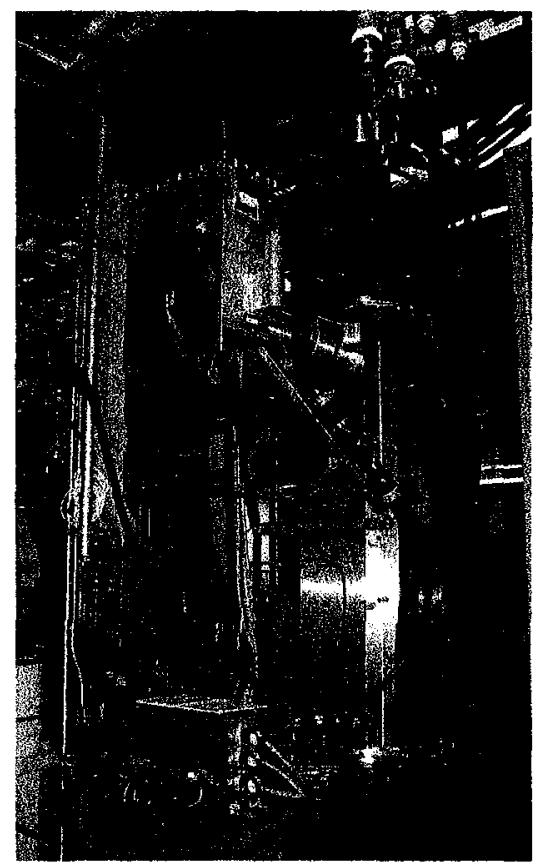

Figure 1: 402.5 MHz, 2.5 MW Klystron

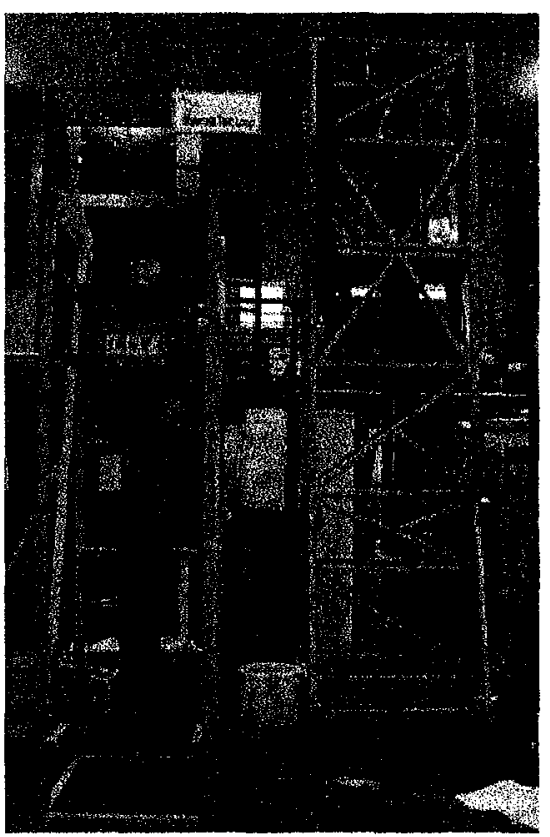

Figure 2: CPI $805 \mathrm{MHz}, 550 \mathrm{~kW}$ klystron on left and Thales $805 \mathrm{MHz}, 5 \mathrm{MW}$ Klystron on right. 
Table 1: SNS Klystron Specifications

\begin{tabular}{|l|l|l|l|}
\hline Vendor & E2V & Thales & CPI/Thales \\
\hline Peak Power & $2.5 \mathrm{MW}$ & $5 \mathrm{MW}$ & $550 \mathrm{~kW}$ \\
\hline Test Power & $2.75 \mathrm{MW}$ & $5.5 \mathrm{MW}$ & $605 \mathrm{~kW}$ \\
\hline Frequency & $402.5 \mathrm{MHz}$ & $805 \mathrm{MHz}$ & $805 \mathrm{MHz}$ \\
\hline Duty Factor & $8 \%$ & $8 \%$ & $9 \%$ \\
\hline PRF & $60 \mathrm{~Hz}$ & $60 \mathrm{~Hz}$ & $60 \mathrm{~Hz}$ \\
\hline Efficiency & $58 \%$ & $55 \%$ & $65 \%$ \\
\hline Beam Voltage & $125 \mathrm{kV}$ & $140 \mathrm{kV}$ & $75 \mathrm{kV}$ \\
\hline Bandwidth & $1.0 \mathrm{MHz}$ & $2.6 \mathrm{MHz}$ & $2.6 \mathrm{MHz}$ \\
\hline Height & $13 \mathrm{ft}$ & $13 \mathrm{ft}$ & $9 \mathrm{ft}$ \\
\hline
\end{tabular}

power each. All other accepted klystrons have met all requirements. However, each of these klystrons has required modification by $\mathrm{E} 2 \mathrm{~V}$ based on the site acceptance tests. We have had a klystron which passed the factory acceptance tests not able to make power at Los Alamos because of a tuning change of unknown origin in the second harmonic cavity. All of the klystrons received have required modifications in the RF joint between the coaxial output and the coax to waveguide transition. The shielding has had to be modified to reduce the x-ray level to a value consistent with the specification. There have been problems with the load on the second cavity being undersized, failing, and in once instance causing a vacuum leak. And we have had problems with the lead shielding shorting out the magnet coils. Fortunately, most of these problems have been external to the vacuum envelope and have been repaired successfully on site.

Three of these klystrons are already installed at SNS and the fourth is in progress. These klystrons have been very easy to install and remove and very easy to condition and operate. They arrive from the factory with all lead shielding and waveguide in place, so that these klystrons are quickly installed and made operational. These kjystrons can typically be brought up to the full peak and average power while maintaining a very low ion pump current value (less than $1 \mathrm{uA}$ ) in less than 1 hour. They have also demonstrated a very low gun and RF arc rate. We execute a 96 hour burn-in test on these klystrons as part of the site acceptance and at the conclusion of this period the arc rate is typically less than 1 event in 24 hours.

The contract for this klystron allowed for a 14 month development. The first klystron was delivered about 11 months late.

\section{$805 \mathrm{MHz} 5 \mathrm{MW}$ Klystrons}

The first of nine $5 \mathrm{MW}$ klystrons has been delivered by Thales and subsequently failed the site acceptance test at Los Alamos. Thales is currently making design modifications external to the vacuum envelope and we will retest the klystron in June. When this klystron was factory tested at Thales they filled their waveguide system with sulfur hexaflouride (SF6) which is required for their RF load and the tests were executed with SF6 in the air side of the output window and output transition of the klystron. When the tube was operated at Los Alamos without the SF6 as called for in the tube specification, the output window and transition experienced severe RF arcing at approximately $1 / 3$ the required peak power. Unfortunately, the output transition was not designed for long term operation with SF6. There was no o-ring seal or barrier window to keep the SF6 from leaking out of the transition and the SNS waveguide system is not filled with SF6. We were able to do a temporary field modification to include a capton window at the output of the klystron waveguide and to install o-ring seals between the transition and RF window. With the application of liberal amounts of silicon gel, were able to temporarily fill the output transition with SF6 and continue testing.

Thales is only able to test to a pulse width of approximately 400 usec at the factory yet the klystron is required to operate with a cathode pulse of $1300 \mathrm{usec}$. The combination of the long pulse with the high peak power is one of the most technically challenging aspects of this tube so we were anxious to validate the long pulse performance. We operated this tube for one month at Los Alamos and for short periods of time (4 to 6 hours) were able to achieve the full peak and average power. The efficiency of our testing and conditioning was impaired by a number of failures. This is the highest peak and average power klystron of the SNS RF system and we had been awaiting its arrival to prove out the performance of many of the waveguide components. With the initial operation of this klystron we discovered design problems with the circulator, the RF load, and the cathode power supply. Temporary and permanent resolutions to these problems impacted the number of hours we could operate the tube. In one month we operated the klystron approximately 112 hours until the cumulative problems in the waveguide systems and transition caused us to suspend testing until permanent repairs and design changes could be made. Testing will resume in June, 2003. With 112 hours of conditioning, the arc rate of the klystron was still high. We averaged either an RF arc or gun arc about every two hours. The tube must demonstrate less than 2 arcs in 24 hours of full power operations before we will accept it.

This klystron is not delivered as an assembled unit. The output transition and most of the lead shielding need to be installed after the tube is inserted in the socket. The insertion and assembly of the first article shielding took approximately 3 days. The x-ray protection of the lead shielding was also discovered to be inadequate and is currently being redesigned by Thales. The contract for this klystron required a 14 month development and this first klystron was delivered about 10 months late.

\section{$805 \mathrm{MHz}, 550 \mathrm{~kW}$ Klystrons}

Two vendors were selected to produce the $550 \mathrm{~kW}$ klystrons. CPI was awarded an order for 75 tubes and Thales was awarded an order for 23 tubes. The contract for these developments also called for the first tube in 14 months. CPI delivered the first tube 4 months late but has 
subsequently delivered 15 tubes and has made up most of the schedule delay. They are currently only 1 tube ( 2 weeks) behind schedule. Thales has yet to deliver the first tube, although it is in transit. They are 11 months behind schedule on the delivery of their first $550 \mathrm{~kW}$ klystron.

We have site acceptance tested 11 of the CPI klystrons and have yet to discover a problem. We accepted the first klystron from CPI to a slightly reduced efficiency specification of $63 \%$. Every subsequent tube has exceeded the efficiency specification. We execute a 36 hour burn-in test on these tubes as part of the site acceptance tests. To date we have seen only 2 gun arcs in approximately 400 hours of burn-in testing with these klystrons. These klystrons require minimal assembly in their delivered configuration. Typically, we can remove a tested CPI tube, install and assemble a new CPI tube, restart testing, and have the tube operating at full peak and average power in under 4 hours.

\section{Circulators}

All SNS klystrons are protected from reflected power by $y$-junction circulators supplied by AFT. These circulators are rated to provide $26 \mathrm{~dB}$ of reverse isolation at any phase of a full power reflection. We have received all 107 circulators at the two frequencies and three power levels from AFT. We have high power tested five of the $2.5 \mathrm{MW}, 402.5 \mathrm{MHz}$ circulators and all have passed. We have also high power tested eight of the $550 \mathrm{~kW}, 805$ $\mathrm{MHz}$ circulators and all passed. We have attempted to site acceptance test the first of the $5 \mathrm{MW}, 805 \mathrm{MHz}$ circulators. Because of the voltage gradients associated with the high peak power, this circulator is filled with SF6. Capton windows are used to restrict the SF6 to the circulator body. While trying to validate the circulator design under high power, we have had multiple failures and persistent arcing problems of the port 2 capton window. AFT has completed some further modeling on this window design and is implementing a new design for the port 2 window. This design will be high power tested in April 2003.

\section{Loads}

All the circulator loads for the SNS RF system are liquid loads where the liquid is the absorptive element. All loads have been delivered. The $402.5 \mathrm{MHz}$ loads, made by Atlantic Microwave, are rated for $2.5 \mathrm{MW}$ of peak power and $200 \mathrm{~kW}$ of average power and use a 70/30 water glycol mix. Six of these loads have been high power tested and all have worked perfectly.

The $805 \mathrm{MHz}$ loads at $550 \mathrm{~kW}$ and $5 \mathrm{MW}$ are pure water loads. The load for $550 \mathrm{~kW}$ application, made by Mega Industires, is rated at $600 \mathrm{~kW}$ peak and $60 \mathrm{~kW}$ average. We have tested 8 of these loads and all worked perfectly. We tested the prototype load up to a peak power of $1.3 \mathrm{MW}$ and an average power of $200 \mathrm{~kW}$ without problem.

The $5 \mathrm{MW}$ peak power, $400 \mathrm{~kW}$ average power load, made by Sure Beam, failed high power testing. On the first 2 loads exposed to high power, an o-ring failed due to exposure to the RF and water leaks developed. The damaged o-ring has been replaced with an o-ring material less susceptible to RF heating and these loads are awaiting retest.

\section{RF Windows}

LANL is providing the RF windows for the DTL and CCL. We are using planar waveguide windows provided by Thales. The power from the $402.5 \mathrm{MHz}$ klystron passes through a single window into the DTL and the power from the $5 \mathrm{MW}, 805 \mathrm{MHz}$ klystron is split and enters the CCL through two windows. All windows have been delivered. We have tested 4 DTL windows and 2 CCL windows. The first pair of DTL windows failed high power testing due to poor RF contacts on the air side of the window. They are being reworked. Thales modified their assembly procedures to correct the problem. A subsequent pair of DTL windows passed the high power testing. A pair of CCL windows has also passed high power testing. Details of the test conditions and the measured performance can be found in reference 1.

\section{Transmitters}

The SNS transmitters comprise all of the electronics to operate and diagnose the SNS RF equipment. They are being provided by Titan System Corporation Pulsed Sciences Division. All twenty transmitters for the normal conducting portion of the SNS linac, test stands, and spares have been delivered to LANL and ORNL and are in various stages of installation and operation. Delivery has just begun on the transmitters for the super conducting linac. A description of the transmitter equipment and test results can be found in reference 2 .

\section{CONCLUSION}

Most of the SNS high power RF hardware has been delivered and good testing progress is being made. The $402.5 \mathrm{MHz}$ RF systems and the $805 \mathrm{MHz}, 550 \mathrm{~kW} \mathrm{RF}$ systems are performing as required. The primary technical risk area is the $5 \mathrm{MW}$ RF systems. Currently the klystrons, loads, and circulators are all being reworked. The arc rate of the klystron is still very high even after over 100 hours of conditioning. This is the area where we will be concentrating our future efforts.

\section{REFERENCES}

[1] K. Cumming, "High Power Testing of the $402.5 \mathrm{MHz}$ and $805 \mathrm{MHz} \mathrm{RF}$ Windows for the Spallation Neutron Source Accelerator", PAC 2003, May 2003.

[2] J. Bradley III, "Spallation Neutron Source High-Power RF Transmitter Design for High Availability, Ease of Installation and Cost Containment" PAC 2003, May 2003. 